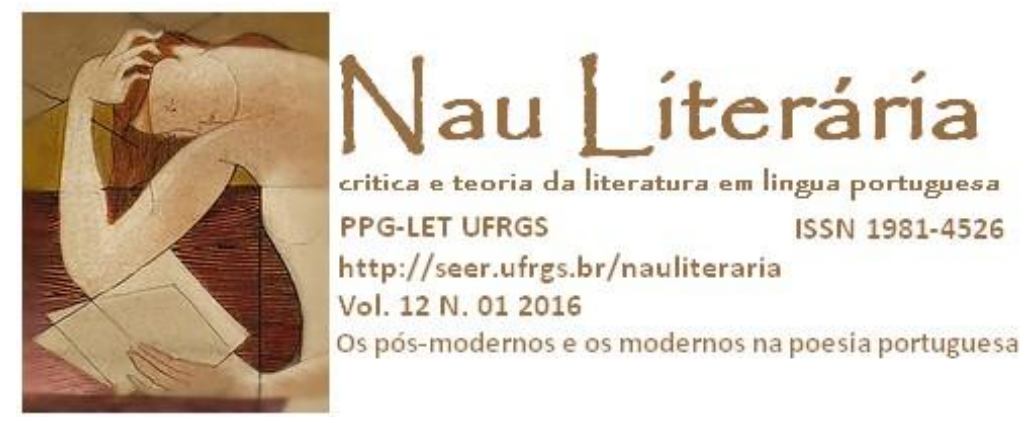

\title{
Um passeio pela galeria de António Ramos Rosa
}

\section{A stroll by Antonio Ramos Rosa's gallery}

\section{Monica Chagas da Costa}

RESUMO: O presente trabalho trata do processo de construção da poesia de António Ramos Rosa em seu livro Do Domínio Plástico (2004). Procura-se ressaltar os elementos intertextuais que são a base dos textos de Rosa, e a relevância do conceito de imagem para a tradução das obras oriundas das artes plásticas para a forma poética. Pode-se perceber como o autor, ao organizar os elementos poéticos em sincronia com as técnicas e imagens de cada artista analisado, se apropria dos textos e coloca seus significados em cheque. $\mathrm{O}$ poema, para Rosa, pode, portanto, ser visto como um espaço múltiplo de recriação e reflexão.

PALAVRAS-CHAVE: Poesia contemporânea portuguesa; António Ramos Rosa; Imagem.

ABSTRACT: The present work deals with the construction process of António Ramos Rosa's poetry in his book Do Domínio Plástico (2005). The intertextual elements which function as the basis of Rosa's texts are highlighted, as well as the relevance of the concept of image for the translation of plastic artworks into poetic form. It is possible to perceive, then, the ways in which the author takes hold of texts and puts their meanings to check, by organizing poetic elements in sync with each analyzed artist's techniques and images. The poem, for Rosa, can, therefore, be seen as a multiple space for re-creation and reflection.

KEYWORDS: Contemporary Portuguese Poetry; António Ramos Rosa; Image. 
O livro Do Domínio Plástico (2004) é uma obra que mistura recepção, leitura, escrita e recriação. O trabalho do poeta vai além da mera criação literária, perpassando a análise de obras das artes plásticas e perfazendo uma curadoria cuidadosa dos elementos mais interessantes dos diferentes quadros e esculturas. Nessa obra, Rosa vagueia por uma galeria propriamente sua, montada com um acervo variado de pintores e pintoras de várias origens, que têm em comum o apelo à sensibilidade e à criatividade do observador. O livro é um caminho a ser percorrido, que se vale primariamente do cultivo do olhar e da cegueira de quem lê. É um livro para ser visto e visitado. O desafio é acompanhar o trajeto visual proposto pelo autor, verificando em poemas específicos os modos como o poeta lida com a arte e a imagem enquanto espaços intertextuais de recuperação dos significados das obras de arte.

A questão mais saliente da coletânea parece se concentrar nos pares contraditórios que sustentam a poesia de Rosa, o que já é apresentado no poema inicial, baseado em um recorte da imagem de Magritte, do quadro "Le domaine enchanté". As combinações binárias não são coincidentais, mas têm nomes bem definidos: olhar e ver, palavra e silêncio, infinito e vazio, espaço exterior e íntimo, nós e ela, proximidade e distância. São essas as diretrizes do livro de Ramos Rosa, é através delas que ele estrutura seu fazer poético. Segundo Nuno Júdice $(2005,33)$ "Há um modelo de poema em Ramos Rosa; e toda a sua obra é um projecto em construção, visando atingir esse poema no fim do que se pode designar como a imensidade de uma escrita. [...] O processo expansivo da escrita não encontra outro limite que não seja o do próprio espaço poético"1

É nesse sentido que o poeta abre o livro, formulando algumas proposições iniciais que se expandem ao longo do poema. A discussão, uma vez que a temática é a da obra de arte plástica, se volta para a imagem. Rosa fala de quadros e obras a partir do que entende por imagem, e não podemos ignorar o quão querido é este conceito para a arte poética. Ele abre seu livro com os versos “O que nos diz a imagem? Diz-nos o que é e não o diz./Porque não é uma palavra. Antes um silêncio,/ uma ausência, um vazio"².

\footnotetext{
${ }^{1}$ P. 33, JÚDICE, Nuno. “A Construção do Poema em António Ramos Rosa” In: MENDES, Ana Paula Coutinho (Org). Poesia do Século XX com António Ramos Rosa ao fundo. Porto: Faculdade de Letras da Universidade do Porto, 2005. p.33 - 39

2 P. 11, ROSA, António Ramos. Do Domínio Plástico. Porto: Asa, 2004.
} 
Podemos tomar a palavra "imagem" como anáfora do recorte da pintura de Magritte apresentado poucas páginas antes, e então estaríamos analisando um caso específico: esta imagem diz-nos o que é e não diz. No entanto, tomando emprestada a expressão de Nuno Júdice, a poesia de Ramos Rosa visa a uma "imensidade da escrita". Ela abrange e se situa no espaço poético (da linguagem), com o qual dialoga ao mesmo tempo em que se refere às formas plásticas. A imagem, portanto, é tanto a imagem figurativa do pintor, quanto a imagem da poesia do autor.

Segundo Octavio Paz, em seu livro $O$ arco e a lira, a imagem poética "contém muitos significados opostos ou díspares, que ela abrange ou reconcilia sem suprimir. [...] A imagem é a marca da condição humana" ${ }^{3}$. Para ele, a contradição é um de seus elementos fundamentais, pois ela se funda na multiplicidade de sentidos possíveis que não se anulam um ao outro; ao contrário, mesmo em um embate fatal, todos eles continuam como partes integrantes. A investigação de Paz segue na direção da discussão sobre existência/nãoexistência, e sobre como, mesmo enquanto criação de um mundo, há algo que escapa ao uso das palavras. Paz e Ramos Rosa, apesar de seguirem por caminhos diferentes, partilham da preocupação com a coexistência de opostos no interior do conceito de imagem.

Isso justifica a escolha de uma figura tão enigmática para sua abertura: a mulhermistério de Magrite, com seus olhos que atravessam o observador, mas que olham para o nada, parece conter em si o paradoxo. A imagem nos diz o silêncio e o vazio. O sentido não é concretude, palpabilidade, mas promessa de sentidos, abertura de leituras. É “Ausência na presença plena" ${ }^{4}$. Esses olhos, que só podem ver porque são cegos, configuram a imagem da própria imagem: ela é vazia em seu sentido (toda visão), mas é "uma infinidade de sentidos,/ou o sentido é infinito" (vê tudo).

A questão do olhar como percepção dos sentidos é essencial para a leitura do resto do livro de Rosa (e, sobremaneira, do poema em questão). Essa observação da imagem é mais do que a simples contemplação do belo ou da arte. É um verdadeiro mergulho no próprio ser, chegando ao "fundo sem fundo do próprio fundo". Ao olharmos para a mulher de Magritte, somos olhados em contrapartida, e a visão da visão nos permite fascinar pelo próprio ato de ver, e, nesse encanto, nos permite reconciliarmo-nos “conosco,/é o nosso

\footnotetext{
${ }^{3}$ P. 104. PAZ, Octavio. O Arco e a Lira. São Paulo: Cosac Naify, 2012. Tradução: Ari Roitman e Paulina Wacht
}

${ }^{4}$ P. 11, ROSA, António Ramos. Do Domínio Plástico. Porto: Asa, 2004. 
coração reencontrado". É possível, em um quadro como este, encontrarmo-nos com o nosso próprio ser, ver o que usualmente se oculta do olhar. No entanto, esse encontro é fruto de um amadurecimento. Ao aprendermos a olhar para o quadro, aprendemos a ver o ser em si, "o centro onde não estamos".

Pensando que o poema nos apresenta a figura como imagem da imagem, é possível chegar à conclusão de que o assunto aqui, mais além do que simplesmente uma análise de um quadro, é a própria natureza da contemplação artística. É como se, ao inscrever na mulher o espelho e o fosso por onde podemos chegar ao próprio ser, Ramos Rosa deixasse oculto, à disposição daqueles com paciência de persistir olhando, uma análise da arte total. Através da contemplação cultivada - não do rápido passeio, não do relance, mas do olhar que se deixa perder na imagem - é possível encontrarmos a nós mesmos, aquilo que faz parte da superfície de tudo, mas é da natureza mais íntima possível.

Esse é o tom de abertura do livro. Não temos aqui uma entrada fácil, pois somos jogados, logo de início, na mais profunda meditação sobre a natureza do ser, da arte, da poesia. Entretanto, o que interessava ressaltar neste primeiro poema já ficou demonstrado: Ramos Rosa apresenta seu livro como uma ruminação sobre o fazer artístico, situando-se na "longínqua proximidade" que a arte oferece para pensar as maneiras como os artistas conhecem o ser, o existir. O processo pelo qual cada pintor passa para chegar à sua arte, então, começa a passar para o primeiro plano nos próximos poemas, que desdobram as questões formais e temáticas de cada artista através das palavras do poeta. Se, em "Le Domaine Enchanté”, a imagem não é uma palavra, nos próximos poemas, no mais alto grau, as palavras são as imagens mais poderosas.

Caminhamos um pouco mais, então, na galeria branca de folha de papel criada por Rosa, passando por figuras de Viera Silva ${ }^{5}$, Miró ${ }^{6}$, Sonia Delaunay ${ }^{7}$, Klee ${ }^{8}$, Manuel

\footnotetext{
5 1908- 1992. Artista portuguesa, naturalizada francesa. Obras: As Bandeiras Vermelhas; A Partida de Xadrez; História Trágico-Marítima; L'Allée Urichante; Landgrave.

61893 - 1983. Artista catalão. Obras: O Carnaval do Arlequim; Números e Constelações em Amor com Uma Mulher; Interiores holandeses I e II.

71885 - 1979. Artista russa. Obras: Rythmes couleures; Carnaval; Valet de Carreau; Composition with triangles and squares.

81879 - 1940. Artista suíço. Obras: Blumenmythos; Angelus novus; Fischzauber; Katze und Vogel;

Aufgehender Stern; Polyphonie.
} 
Baptista $^{9}$, até chegarmos a um poema retirado do livro de 1966, Estou Vivo e Escrevo Sol, sobre Göetz.

Henri Göetz foi um artista americano, de família francesa, nascido em 1909 e falecido em 1989. Formado pelo MIT, mas influenciado pela convivência com os pintores surrealistas das primeiras décadas do século XX (com quem conviveu e travou amizades), o pintor desenvolveu técnicas de pintura diferenciadas. Sua história de produção atravessa a Resistência Francesa na Segunda Grande Guerra, e chega ao quase final de século com

dezenas de quadros espalhados por galerias e institutos ao redor do mundo ${ }^{10}$. Sua relação com Picasso, Kandinsky, Braque e Breton conferiu-lhe as credenciais da pintura surrealista, sem que, no entanto, suas obras fossem (na maioria) figurativas. Nos quadros de Göetz aparecem tons fortes de vermelho, azul, e verde, formas com contornos definidos, geralmente centralizadas na tela. Seu nome, na galeria de Ramos Rosa, faz sentido devido à forte presença dos nomes com quem conviveu e trabalhou.

Tomando emprestado da pintura a disposição de quadros conhecida como tríptico, os poemas-leitura, ou poemas-imagens, baseados na obra de Göetz são três, sendo o último mais extenso que os outros. É interessante notar que Rosa se apropria das cores encontradas nas obras do pintor, concentrando em cada poema uma combinação diferente. No primeiro, as cores dominantes são o preto, o verde, o dourado e o branco. No segundo, vermelho e negro. No terceiro, verde, vermelho, azul, preto, branco e rosa.

\section{GÖETZ}

São os troncos troncos e um monte puxado para o sol obliquamente.

E a terra é de carvão, mar de raízes e o sol dourado de limão, quase oculto, estende-se sobre o verde da folhagem. Uns fogachos brancos rompem sonoros.

Não se tinha contemplado ainda a porta.

Era vermelha sob a fechadura negra.

Pela fresta, o espaço era verde acinzentado.

E duas cordas ao lado, atravessadas

por um ponto de interrogação horizontal

${ }^{9} 1936$ - . Artista português.

10 Informações retiradas de: http://rogallery.com/Goetz Henri/goetz-biography.html (em 12/08/14) 
caíam musicais.

A praia era de guitarras destruídas, voos negros rosados sobre azul

e sobre o branco multiplicado do céu cantava o azul, cantava o branco sol e azul

e os fragmentos de guitarras verdes vermelhos negros

cantavam mar azul, praia vermelha,

voos de andorinhas negros.

(ROSA, António Ramos. Do Domínio Plástico. Porto: Asa, 2004, P. 37.)

O poema de Goetz começa, pois, verticalmente: "São os troncos troncos e um monte". Segundo Tzvetan Todorov ${ }^{11}$, o momento em que decidimos interpretar um discurso determinado é sempre indicado por determinados elementos textuais que podem ser sintagmáticos ou paradigmáticos. A repetição é um dos índices sintagmáticos que sinalizam a necessidade de interpretação. Portanto, quando Ramos Rosa repete as palavras "troncos troncos", é preciso que busquemos interpretar o que elas significam dentro do poema. A abertura do texto com esses elementos repetidos indica uma direção de leitura que se aprofunda na obra de Goetz. O observador, que é, no caso, Ramos Rosa, acompanha as figuras verticais dos quadros do pintor e as incorpora em sua própria poesia, fazendo com que esses elementos se tornem parte de seu próprio arsenal poético. Portanto, os "troncos troncos", que deflagram uma imagem de múltiplas figuras verticais, uma ao lado da outra, remetem tanto às figuras plásticas quanto às linhas direcionais da interpretação.

No entanto, logo depois, o verso segue com "um monte", que torna as linhas mais sinuosas e mais flexíveis, uma vez que ele não é simplesmente um monte em uma paisagem horizontal, ou então um monte recortado de outros contextos, mas está ao lado dos "troncos troncos" e é puxado obliquamente em direção ao sol. Desse modo, a poesia abre com um olhar que se insere dentro da obra de Goetz, não de maneira direta e precisa, mas de forma obliqua, análoga aos raios solares que incidem sobre a Terra a partir de um ângulo não reto, iluminando apenas partes. As linhas do poema de Ramos Rosa não são paralelas, nem mesmo retas, são como a obra do pintor: são orgânicas e funcionam como harmonização de diversas imagens que não se fundem ao se sobreporem e interagirem entre si.

11 TODOROV, Tzvetan. Symbolisme et interprétation. Paris: Seuil, 1978. La symbolique du language. P. 2387. 
Na mesma estrofe, o poeta dá qualidades aos elementos representados nas telas de Goetz $^{12}$. A poesia de António Ramos Rosa já é em si uma interpretação dos quadros, e ela coloca os elementos que ele enxerga nas pinturas. O primeiro deles é a terra, feita de carvão: ou seja, uma terra escura, seca, que acaba influenciando todo o seu entorno, pois o carvão é uma substância que se imprime no mais fácil contato. Contudo, essa terra é circundada por um "mar de raízes", que incorpora elementos mais orgânicos que o carvão, com mais vida que o anterior. Essa base, terra e mar, que são transmutados em relação aos objetos naturais (terra em carvão, mar em raízes), é iluminada por um sol que, como o natural, é dourado, mas que também se transforma e obtém qualidades de uma outra ordem, pois é “dourado de limão". Ele é quase lúdico, fresco ao mesmo tempo em que ácido.

Tais elementos básicos, a terra, o mar e o sol, são todos transformados, aproximando-se do natural, mas modificados para entrar na arte a partir de um olhar diferenciado. O sol, entretanto, não é completamente aparente, pois é oculto sob o verde das folhagens. Nesse trecho, há uma aparente organicidade que é comum à obra de Goetz, e que fica mais presente com as folhas. $\mathrm{O}$ verde, bastante usado em suas pinturas, cobre o sol, e isso aponta para um ambiente mais soturno, ainda que não frio ou morto, pois os elementos como o sol, as folhas e as raízes são vivos.

A estrofe se completa com um verso que une dois sintagmas bastante diferenciados tanto dos precedentes, quanto entre si. Ele une "fogachos brancos", que seriam elementos claros da pintura (até agora os tons permaneciam escuros, com troncos e montes, geralmente relacionados com cores sombrias, bem como o carvão e as raízes; o sol dourado sendo uma exceção) com "sonoros". Todos esses elementos escurecidos são cortados por esses fogachos, que rasgam essa pintura em partes de maneira musical.

O poema, de modo geral, trata da musicalidade das imagens de Goetz. Este é o primeiro elemento que aponta para a sonoridade das formas que o pintor escolhe para retratar. Se até então tudo parecia ser silêncio (terra, sol e mar), agora o fogo abre o som, e liberta o observador para outra percepção da imagem.

A segunda estrofe pode ser interpretada como uma ligação entre a primeira e a última. Ela inicia com a tomada de percepção apontada pelos fogachos brancos, uma vez

12 É importante notar que o pintor não costumava utilizar elementos figurativos em suas obras, e sim formas abstratas que podem ou não ser relacionadas com figuras conhecidas. 
que o eu lírico chama atenção para um elemento até então despercebido, que se torna objeto de contemplação. Ele não é um elemento natural, mas fabricado: a porta. Ela pode ser vista como uma figura representativa de um objeto real, ou como, também, uma porta metafórica, que abre o olhar do observador para outra percepção, que se atualiza através de certas cores.

O poema traz tonalidades mais fortes e pesadas, como o vermelho e o negro. Tradicionalmente, o vermelho é relacionado com a morte, o sangue, elementos mais passionais da existência humana. Portanto, uma vez que interpretemos essa abertura como "vermelha", ela se apresentaria como uma percepção bastante intensa, tanto da arte como da própria vida. Esta porta, ainda, é aberta com uma fechadura negra, ou seja, por uma cor que é relacionada frequentemente com o luto, a dor, a solidão e a escuridão. Desse modo, esta é uma passagem que não é tranquila ou pacífica, e que é marcada por algum tipo de luta passional, que se trava dentro de algum tipo de sofrimento ou sentimento intenso e, muito provavelmente, negativo. Contudo, mesmo através desta turbulenta passagem, uma fresta deixa ver um espaço verde, ainda que com contornos acinzentados. Assim, é possível retomar os elementos anteriores do poema (a terra, o mar, os troncos, as folhagens), mesmo através dessa difícil travessia. Apesar disso, a direção do olhar se transforma, pois os elementos direcionais (as linhas do poema) mudam de orientação. Se na primeira estrofe tínhamos os troncos e o monte que se repetiam e apontavam para uma verticalidade, aqui temos duas cordas verticais que são atravessadas por um ponto de interrogação horizontal.

A horizontalidade entra no poema depois da travessia com um aspecto de dúvida. O que antes era um mergulho profundo em um tema, começa a se tornar um olhar mais amplo que se questiona sobre o horizonte, sobre o contexto desses elementos que são verticalizados. A natureza dessas cordas é particular: elas não amarram ou prendem o observador, ou o eu lírico, mas elas caem "musicais". Novamente, o elemento sonoro se destaca no poema. Notemos que ambos os versos que trazem a musicalidade, até então, são os últimos de cada estrofe, e a sonoridade se apresenta somente na última palavra.

As duas cordas não somente adquirem qualidades musicais, mas o fazem através de uma queda, que é atravessada por uma interrogação. Isso que nos leva à terceira estrofe, que apresenta a imagem de uma praia, que não é totalmente estranha às anteriores, principalmente às apresentadas na primeira estrofe, uma vez que o poeta fala de terra e mar 
que normalmente se encontram em uma praia. Ramos Rosa agora se fixa nesse entre lugar, onde o carvão da terra e as raízes do mar se cruzam e se encontram. Nesse ponto de intersecção, o elemento sonoro e musical do poema se mostra mais abertamente, uma vez que a praia não é formada de areia ou árvores, nem mesmo pelos troncos ou pelas raízes já mencionadas no texto, mas feita de guitarras destruídas. Ou seja, as cordas que caíam, possivelmente as cordas de uma guitarra, nos levam até uma praia que é feita desses destroços. É preciso lembrar que o poema passa por um momento de destruição, por uma travessia que é, muito possivelmente, sangrenta, avermelhada, e então, as guitarras não se mantêm por inteiras. Elas são destruídas, esfaceladas nessa praia, e, sobre elas voam cores.

Não há, em primeira análise, objetos concretos que passem por cima da praia que Ramos Rosa enxerga na obra de Goetz, mas sim cores que se mesclam, e que apontam para algumas possibilidades, para alguma esperança depois da destruição. Por mais que os voos sejam negros, eles são "voos negros rosados", ou seja, possuem uma tonalidade que suaviza o negror e que se destaca sobre azul e sobre o branco multiplicado do céu. Os elementos de negatividade começam a se dispersar com o rosado, vêm de cima, mas estão apenas cobrindo um céu que é branco e onde o azul canta. O azul, uma cor tradicionalmente relacionada à tranquilidade, à paz (por mais que também ligada a sentimentos de tristeza to be blue no inglês significa estar triste), é um elemento que suaviza a experiência anterior, que é a traumática experiência do vermelho.

A ligação entre as cores e os sons é uma das marcas mais fortes dessa última estrofe, uma vez que elas, nesse momento, cantam. Elas explodem os limites da representação plástica e adentram o âmbito sonoro, que é mais próximo do observador. Elas tocam muito mais contundentemente àquele que as observa, porque não permanecem simplesmente na tela, mas se deixam ouvir. Elas abarcam mais que um sentido: são tanto visão quanto som. Dessa maneira, o elemento azul que clareia o poema, que traz a ideia de esperança que supera o sofrimento, é muito mais próximo do observador do que o elemento da tragédia ou do sofrimento.

O canto é branco, sol e azul: é luminoso, trazendo uma força positiva à intenção da imagem. Os elementos negativos ou fragmentados não são esquecidos ou apagados. Eles continuam em evidência. Não é possível desmanchar a travessia da porta vermelha; ela continua fortemente representada. No entanto, esses fragmentos que agora tomam diversas 
cores (verdes, vermelhos e negro), trazem a experiência anterior, mas cantam o mar azul, cantam o elemento de luminosidade e esperança, ao mesmo tempo em que cantam "praia vermelha,/voos de andorinhas negros". Podemos entender, assim, que o olhar que Ramos Rosa tem sobre a obra de Henri Goetz entende a sua harmonização desses elementos contraditórios: a positividade, a luminosidade ao mesmo tempo em que se tem a escuridão e a dor. Todas essas facetas aparecem nas figuras e nas obras de Goetz de forma harmoniosa, são equilibradas.

Durante o primeiro poema, “Le Domaine Enchanté”, Ramos Rosa preza justamente o equilíbrio supremo das contradições entre interno/ externo, próximo/ longínquo, tudo/ nada. Nesse poema, que acabamos de analisar, o poeta retoma a ideia da harmonia, justamente porque a encontra na obra do pintor americano-francês. No entanto, ele não traduz a obra de Goetz como lida com a obra de Magritte, ou de Braque, ou de Manuel Batista. Ele dá a cada poema um tratamento que esteja de acordo com a forma plástica de cada obra. Portanto, cada texto incorpora uma outra voz, um outro olhar, que não é o de Antonio Ramos Rosa, mas com o qual o poeta consegue se identificar a ponto de o tomar para si, e utilizar para a sua poesia.

A obra do poeta, assim, coloca em questão o que Mikhail Bakhtin ${ }^{13}$ fala sobre a linguagem da poesia, ou o discurso na poesia, uma vez que ele aponta que o dialogismo é uma característica do romance, e que a poesia é um gênero completamente monológico, já que ela não admite em si a expressão de uma outra linguagem que não seja do próprio poeta. Não é o caso de dizer que a obra do poeta é completamente dialógica, uma vez que existe um eu que fala de si ao longo do livro, por mais que, por exemplo, no poema de Goetz, não haja uma expressão de primeira pessoa direta. Ainda assim, há um olhar, que é de um observador em particular, que atravessa um caminho de contemplação que começa nos troncos, passa pela porta e chega até a praia. É esse eu que fala no poema, e é um eu que vai falar em cada poema que Ramos Rosa apresenta em Do Domínio Plástico.

No entanto, ainda que seja possível concordar com a citação de Bakhtin a seguir, surge uma questão sobre a sua total validade:

13 BAKHTIN, Mikhail. Questões de literatura e de estética: a teoria do romance. São Paulo: Editora Hucitec, 1990. Tradução: Aurora Fornoni Bernadini, José Pereira Júnior, Augusto Góes Júnior, Helena Spryndis Nazário, Homero Freitas de Andrade. 
A língua do poeta é sua própria linguagem, ele está nela e é dela inseparável. Ele utiliza cada forma, cada palavra, cada expressão no seu sentido direto (por assim dizer, "sem aspas"), isto é, exatamente como a expressão pura e imediata do seu pensar. [...] Tudo o que vê, compreende e imagina o poeta, ele vê compreende e imagina com os olhos da sua linguagem, nas suas formas internas, e não há nada que faça a sua enunciação sentir a necessidade de utilizar uma linguagem alheia de outrem. ${ }^{14}$

Essa citação se coloca como problema para olhar a obra de Ramos Rosa, em particular neste livro, uma vez que ele incorpora elementos de outras linguagens, por mais que não linguísticas, mas plásticas, para dentro do próprio processo de criação poética. Desse ponto de vista, não é possível dizer que ele não sente "a necessidade de utilizar uma linguagem alheia", mas, ao mesmo tempo, ele não a utiliza como realmente outra, uma vez que ele a introjeta para dentro do próprio pensar e do próprio escrever que se faz ao longo do livro.

Esse é o aspecto mais interessante da sensibilidade do poeta: ele é capaz de captar a linguagem e a intenção do artista e dialogar com elas, tornando-as um pouco suas também. Por essa razão, é impossível distinguir, nos quadros expostos na nossa galeria, a assinatura de autor ou de pintor: elas se fundem na poesia. O sucesso dos poemas está intrinsecamente ligado a essa fusão. É possível, através dela, perceber o cuidadoso trabalho do escritor que observa, sente e entende as obras que vê, e sabe que, como aponta no último poema, por mais que tente pintar/escrever o que vê, o seu modelo é sempre um pouco de si.

\section{REFERÊNCIAS}

BAKHTIN, Mikhail. Questões de literatura e de estética: a teoria do romance. Tradução: Aurora Fornoni Bernadini, José Pereira Júnior, Augusto Góes Júnior, Helena Spryndis Nazário, Homero Freitas de Andrade. São Paulo: Editora Hucitec, 1990.

14 P. 94. BAKHTIN, Mikhail. Questões de Literatura e de Estética: A Teoria do Romance. São Paulo: Editora Hucitec, 1990. Tradução: Aurora Fornoni Bernadini, José Pereira Júnior, Augusto Góes Júnior, Helena Spryndis Nazário, Homero Freitas de Andrade 
JÚDICE, Nuno. A construção do poema em António Ramos Rosa. In: MENDES, Ana Paula Coutinho (Org). Poesia do Século XX com António Ramos Rosa ao fundo. Porto: Faculdade de Letras da Universidade do Porto, 2005. p.33 - 39.

PAZ, Octavio. O arco e a lira. Tradução: Ari Roitman e Paulina Wacht. São Paulo: Cosac Naify, 2012.

ROSA, António Ramos. Do domínio plástico. Porto: Asa, 2004.

TODOROV, Tzvetan. Symbolisme et interprétation. Paris: Seuil, 1978. La symbolique du language. p. 23-87. 